Brit. J. industr. Med., 1961, 18, 41.

\title{
A STUDY OF ASPERGILLUS SPORES IN THE ATMOSPHERE OF A MODERN MILL
}

\author{
BY \\ F. C. STALLYBRASS* \\ From the Department of Bacteriology, Royal South Hants Hospital, Southampton
}

(RECEIVED FOR PUBLICATION AUgUST 16, 1960)

\begin{abstract}
A study has been made of the atmospheric pollution by aspergillus spores of a large animal provender mill in which various grains are unloaded, stored, and processed, and a comparison has been made with the degree of pollution of the urban atmosphere in the neighbourhood. The catch-rate of the spores in the normal working atmosphere of the mill has been found to be 30 times higher than that obtained in the urban atmosphere, and for this reason the health record of a group of operatives has been considered with particular reference to the occurrence of pulmonary aspergillosis. Despite the risk of exposure within the mill no evidence has been found of an increased liability to develop the disease.

The particular groups of aspergilli isolated by culture during this study have all been reported to have been associated with aspergillosis in man, and the relevant papers give evidence of a pathogenic rather than a saprophytic role. The study therefore provides quantitative data relating atmospheric spore content and the risk of pulmonary infection in man, a subject which as yet has received little attention.

In this study it has been found that of all the grains handled in the mill, maize is associated with the highest degree of contamination, so that the aspergillus spores in the atmosphere of the mill may have originated chiefly from this source.
\end{abstract}

The association between aspergillosis and grain has been known since Dieulafoy, Chantemesse, and Widal (1890) described the disease as an occupational hazard of pigeon-crammers. Reports of particular interest are those of cases in which the fungus has been isolated from human lesions and identified, and in which evidence is given both of the pathogenic role of the fungus and of the probable mode of infection. Such reports related to $A$. nidulans (Holden, 1915), A. versicolor (Steele, 1926), A. flavus (Wahl, 1928), A. fumigatus (Hertzog, Smith, and Goblin, 1949), and A. niger (Utz, German, Louria, Emmons, and Bartter, 1959), while $A$. clavatus was included by Hinson, Moon, and Plummer (1952). A. glaucus has been reported only infrequently (Cawley, 1947). It seems strange, therefore, that those who have specially studied pulmonary disease, which occurs in men working in contact with grain, find little to say on aspergillosis. Wohlhueter, Kleitz, Kraft, and Mourot (1940) studied chest disease in 10 millers and bakers, and in these the lesions were associated with silica

* Present address: Department of Bacteriology, University College Hospital, London, W.C.1.

4 dust rather than aspergillus spores. Similarly, Dunner, Hermon, and Bagnall (1946), who studied the lung changes in the grain dockers of Hull, found no aspergillosis. Dunner, Hardy, Nakielny, Robinson, and Smart (1958) examined 31 men who habitually handled grains of all sorts and in none of these was there evidence of pulmonary mycosis. There is no doubt that moulds flourish in grain, and that persons exposed to grain sometimes develop pulmonary aspergillosis; nevertheless, such an event seems to be rare, and there is only one recorded case of compensation being awarded to a man who developed aspergillosis after working with hay, grain, and corn for more than 20 years (Ford v. Union Stock Yards, 1942). It is probable that grain dockers are scarcely exposed to the dust, and this may account for the absence of aspergillosis in these people, although Dunner et al. (1946) suggest that where pneumatic elevators are not used the amount of dust in the holds may be considerable. Referring to the epidemiology of the disease Ainsworth and Austwick (1959) considered that all mammalian aspergillosis was probably a primary pulmonary disease contracted by inhalation of large 
numbers of fungal spores, and that the quantitative relation of spores to infection appeared to be the key to the epidemiology and pathology of aspergillosis. This opinion is not new for it was expressed by Raether (1912) who stated that man was relatively immune to aspergillus infections and that a large infecting dose was necessary, and by Coe (1945) who suggested that "the principal factor in the pathogenesis of the disease in man seems to be exposure to repeated massive dosage".

Nothing has been found in the literature of work which provides quantitative data on this subject. The present study has been undertaken in order to determine (a) the frequency of occurrence of aspergillus spores in the atmosphere of an animal provender mill, and to compare this frequency with that found by similar means at selected sites elsewhere in the neighbourhood at the same time of year; (b) whether there is any association between the presence of aspergillus spores in the atmosphere and the type of grain being moved at the mill; and (c) the existence of any associated liability of the mill operatives to develop pulmonary aspergillosis.

\section{Method}

Petri-dishes $9 \mathrm{~cm}$. in diameter and containing Sabouraud's medium were exposed to the atmosphere at selected sites for known periods of time. The cultures were incubated at room temperature regulated as far as possible to $22^{\circ} \mathrm{C}$. and the total number of colonies growing on each plate was counted after four days, at which time seedling colonies would not be apparent. Incubation was continued until the seventh day when all colonies of aspergilli were counted, and a percentage figure calculated.

This was the basis of the counts, but in practice it was found impossible to keep strictly to the times. The number of colonies growing on each plate varied considerably, depending on several factors including exposure time and spore concentration, and the morphological characteristics of colonies varied according to the degree of crowding on the plate. Sometimes the aerial mycelium was produced on or before the fourth day, at which time any recognizable aspergilli were noted, while on occasions its production was delayed until the seventh day. On the other hand, in preliminary experiments it was found difficult to make an accurate total count on the seventh day because of colonies becoming contiguous. For these reasons it was found best to make the total count on the fourth day and to count the aspergilli when recognition could be certain. To begin with all suspected colonies were identified by means of Sabouraud slide cultures incubated at room temperature. Aspergilli were later identified by means of a $\times 12$ hand lens, and slide cultures were employed only when the appearance was atypical.

In addition to the defects of the method already mentioned it was recognized that the results were influenced by several other factors. When the total number of colonies was 200 or more per plate the count became difficult and the error increased, while, when the total colonies were few, it was impossible to calculate an accunatapnesentage figure for the aspergilli. There was also the inaccuracy associated with the periodic growth of spreading moulds which in preliminary experiments rapidly covered the whole plate. This difficulty was overcome by inspecting the closed plates every day and by excising the colonies before they became too large. It was necessary only rarely, to excise such a colony before the third day and at the time of excision all the other colonies included in the zone were counted and added to the total count. Aspergilli in the zone were of course not recognized, but this source of error tended to diminish rather than to increase the aspergillus count. It was found that spreading moulds were not as common as might have been expected; nevertheless, several experiments were rendered valueless and the results were not recorded.

It is not easy to determine with consistent accuracy the spore content of a number of greatly different air samples. The method employed here has the advantage of simplicity and the importance of this outweighs the significance of its obvious defects.

\section{The Mill}

In order to understand the type of air samples which were examined a brief description is given of the mill where the experiments were performed.

All the grain is withdrawn from the ships by means of pneumatic elevators (Fig. 1) and is passed on to a moving belt in a gantry whence the grain is conveyed to the main silo. During the process of unloading a ship a large quantity of dust is produced in the gantry especially at the point where grain is transferred from the elevator to the conveyor belt.

Operatives are not constantly employed at this site, but while the elevator is in action respiration is impossible for any length of time without some protection. During preliminary experiments plates were exposed at the head of the elevator, but the conditions were unbearable and the plates were too heavily inoculated; because of these difficulties all other plates exposed in the gantry were opened at some distance along the conveyor (Fig. 2).

The silo comprises numerous large store-bins and has a total capacity of 20,000 tons of grain. The grain is transferred from ship to silo or from one compartment to another within the silo itself by means of conveyor belts; these traverse the roof of the silo and empty grain by means of shutes into individual bins. Usually, but not always, a dust extractor is placed near the shute, and a moderate amount of dust is present at these sites and in the general atmosphere of the silo-top. For this study plates were exposed at the points where grain disappeared down the shutes. 


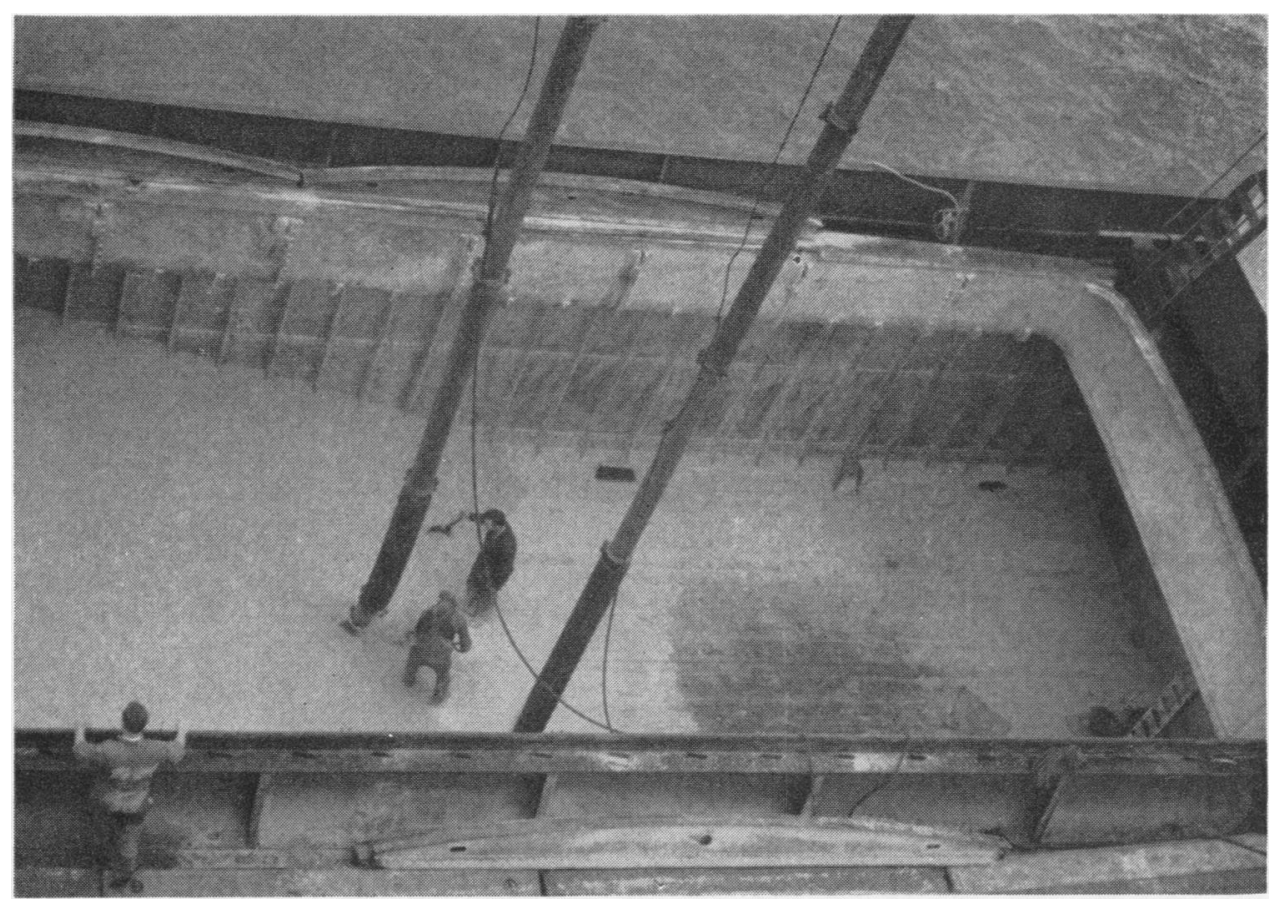

FIG. 1.-The pneumatic elevators and ship's hold.

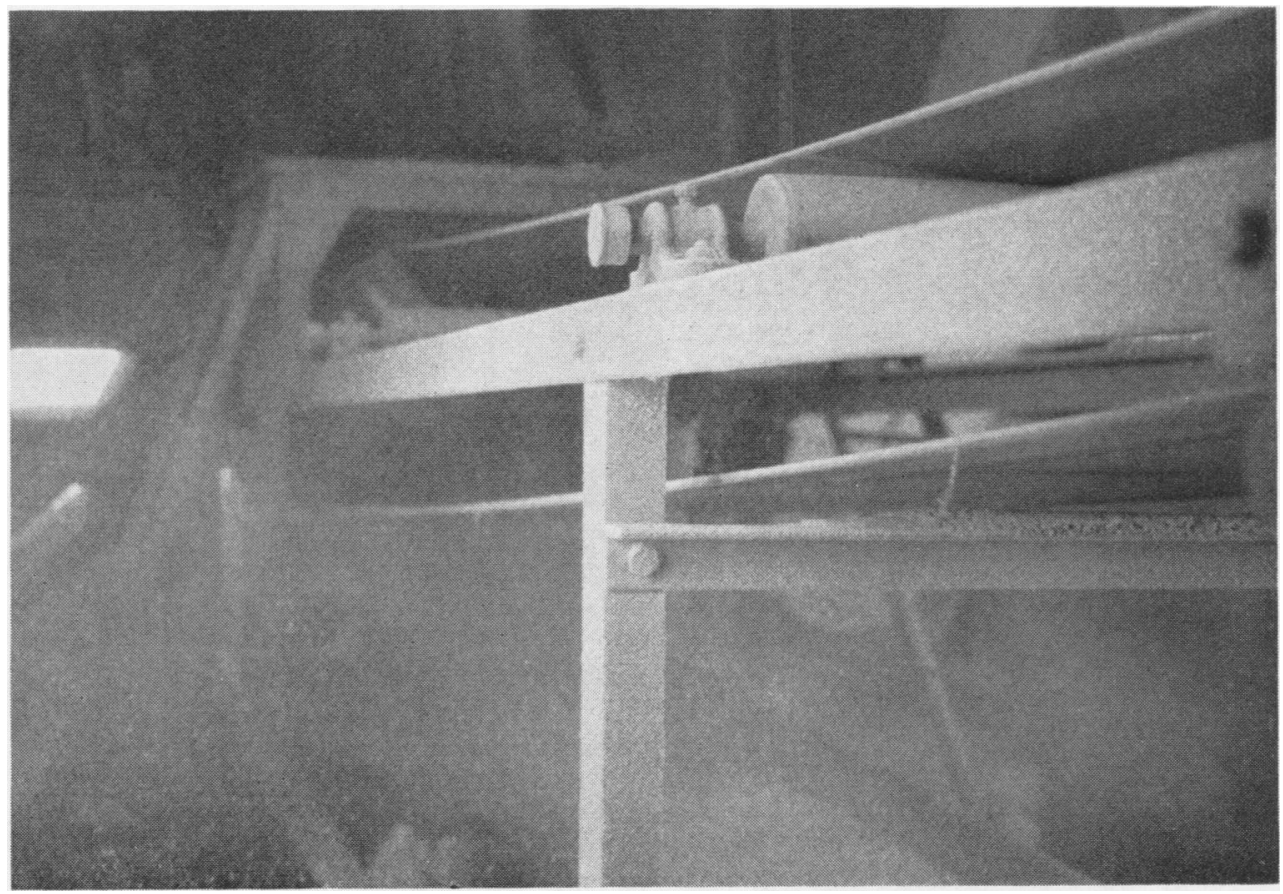

FiG. 2.-Conveyor belt in gantry. 
TABLE

RELEASE OF ASPERGILLI INTO ATMOSPHERE AND CONVEYANCE OF DIFFERENT GRAINS

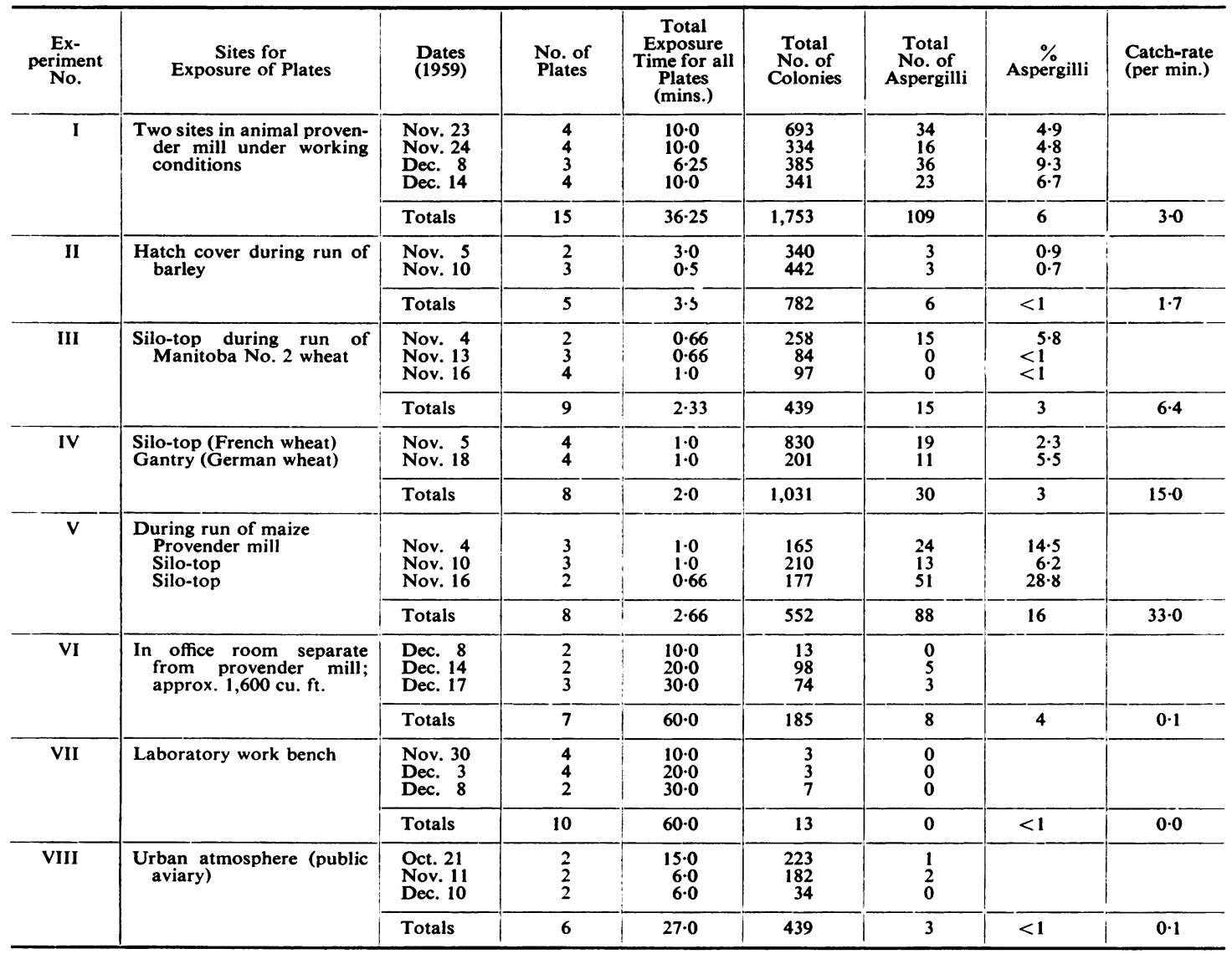

From the silo, grain is transferred either to the flour mill or to the animal provender mill. The former includes the largest part of the mill, but as the machines are wholly enclosed the atmosphere is dust-free. For this reason no plates were exposed in the flour mill. All the grain used in animal feeding-stuffs (e.g. maize, oats, and barley) is transferred to the animal provender mill, movement within the mill being effected by conveyor belts and covered worm-screws. The atmosphere is dusty but not uncomfortable. Plates were exposed at the opened hatch-covers of the worm-screws, in order to associate spore counts with certain types of grain, and at two sites elsewhere in the animal provender mill in order to determine the spore content of the general atmosphere.

For comparison, control plates were exposed in an office room which was separate from the mill proper and where the atmosphere was apparently dust-free, in the laboratory where the cultures were handled, and in the open but protected atmosphere provided at the public aviary in the centre of the town. All the birds in the aviary were in normal health and there was no reason to suspect aspergillosis in any of them. Two birds died during the time of the experiments but autopsy and histological examination showed no evidence of fungal disease.

\section{Results}

During 1952, Richards (1956) carried out a spore survey of Great Britain, and his site for exposing plates at Southampton was the Department of Botany, University of Southampton. His data show that there was $0.56 \%$ aspergilli with a catchrate of 0.02 per minute. These figures agree with my own obtained for the laboratory and for the urban atmosphere. In the atmosphere in the 
office room it can be seen (Table) that the percentage of aspergilli is higher, although the catchrate is still very low. The atmosphere in the animal provender mill, however, gives a catch-rate for aspergilli $\mathbf{3 0}$ times as great, and it is reasonable to suppose that operatives working here inhale, during working hours, 30 times the number of aspergillus spores inhaled by other workers in offices and in the open air.

In experiments II to $\mathrm{V}$ (Table) some attempt was made to determine whether the release of aspergilli into the atmosphere was associated with the conveyance of any particular type of grain. The number of samples was limited because grains were tested only when run for normal milling purposes. Consequently, choice of grain was not always possible, and certain grains were run only infrequently. The figures refer to threshed grain, so that although all samples included a certain amount of dust, more dust and higher figures could be expected from unthreshed grains. The hard wheats were relatively clean, while some samples of unsorted maize included particles of cob. It can be seen from experiment $\mathrm{V}$ that maize is associated with a higher concentration of aspergillus spores than any of the other grains tested; the catch-rate (in a moving atmosphere) is also high (33 per minute). The significance of this in relation to the importance of maize in the preparation of animal and poultry feeding stuffs remains to be determined.

At the time of the present investigation a total of 84 employees had duties to perform in the gantry, silo-top, or the animal provender mill, all of these being situations where the dust content of the atmosphere is above normal. Of these 84 employees 70 had duties confining them to the animal provender mill while 14 were employed elsewhere but nevertheless made frequent visits to the gantry, silo-top, or animal provender mill. In the first group 41 had been employed in the provender mill for over three years, while of the second group 12 had had the same mode of employment for this time.

It would have been more satisfactory to have been able to compare the incidence of pulmonary aspergillosis in two populations but the comparative rarity of the disease and the fact that it is not separately coded in the International Classification of Diseases makes an analysis of this sort impossible. For this reason information was sought concerning the claims for injury and disability arising in connexion with the work of the mill operatives.

Between December 1956 and December 1959 a total of 31 employees of the firm sought compensation for disease or injury arising out of their work; none of these was claiming for chest disease. Moreover, during the eight-year period December 1951

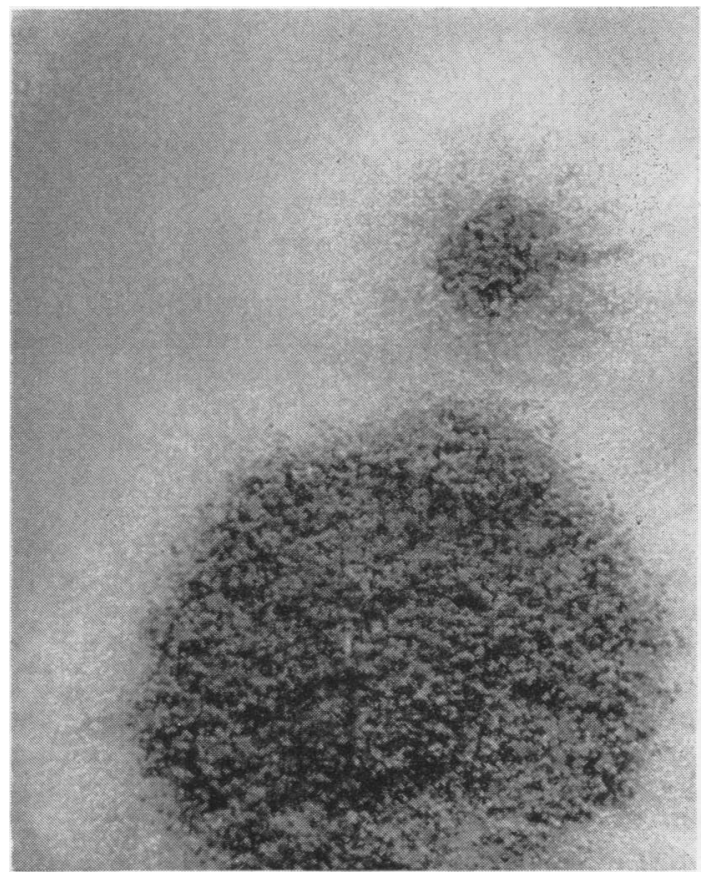

Fig. 3. - A. clavatus, $\times 2 \frac{1}{2}$. Sabouraud agar.

to 1959 when the present machinery in the mill has been in use without major modification, no single case of pulmonary aspergillosis has been reported. The disease, in fact, is unknown at the mill. It seems, therefore, that millers show no special liability to mycotic pulmonary disease even though they may be exposed for a long time to an atmosphere with a high spore content.

The actual numbers of employees just quoted refer only to the three-year period between December 1956 and December 1959 because it was felt that a more accurate record of the type of employment would be gained by restricting the time covered to this limit. It may be argued that the three-year period is too short a one in which to expect any claim for pulmonary aspergillosis to be made but the author knows of no evidence to suggest that a more prolonged exposure is necessary to cause infection, although duration of exposure will naturally influence the development of the disease by prolonging the daily risk of inhaling an infective atmosphere.

During the experiments aspergilli belonging to several groups and species were isolated. These included $A$. amstelodami, $A$. repens, $A$. ruber, A. clavatus (Fig. 3), A. flavus, A. fumigatus, and $A$. niger. These and the $A$. glaucus group have at one time or another been incriminated as human 
pathogens, so that the experiments provide some evidence of the significance of spore content of the atmosphere in the causation of human pulmonary aspergillosis. It seems that this disease does not result from inhalation of an atmosphere associated with a catch-rate for aspergilli of 3.0 per minute or less. It may have been for this reason that Dunner et al. (1958) failed to associate fungi of any genus with 30 out of 31 grain workers who had had chest symptoms. In the single case in which fungi were demonstrated in the lungs at autopsy identification was not complete, and the fungus was not an aspergillus.

The experiments also show that so far as some mill operatives are concerned, there may be temporary exposure to a potentially more infective atmosphere. For example, experiment III (hard wheats) shows a catch-rate of 6.4 per minute, experiment IV (soft wheats) 15.0 per minute, and experiment $V$ (maize) 33.0 per minute; these high figures are partly the result of air movement near the conveyor belt where the plates were exposed, but they are nevertheless worthy of consideration. No data have been obtained for unthreshed grain and it would be of interest to obtain figures for the atmospheric spore content under threshing and stable conditions (Tscherniak, 1928).
I am pleased to acknowledge the assistance of Dr. J. Walker of the Mycological Reference Laboratory for help in identifying the aspergilli; and the courtesy of Messrs. Joseph Rank Ltd., Southampton, F. T. Everard and Sons Ltd., and the British Transport Commission.

\section{REFERENCES}

Ainsworth, G. C., and Austwick, P. K. C. (1959). Fungal Disease of Animals, 1st ed., pp. 10, 12 . Commonwealth Agricultural Bureaux, Farnham Royal, Bucks.

Cawley, E. P. (1947). Arch. intern. Med., 80, 423.

Coe, G. C. (1945). Ann. intern, Med., 23, 423.

Dieulafoy, G. Chantemesse, A., and Widal, G. F. I. (1890). Gaz. Hôp. (Paris), 63, 821.

Dunner, L., Hardy, R., Nakielny, E., Robinson, L. R., and Smart, G. A. (1958). Brit. J. Tuberc., 52, 291.

-, Hermon, R., and Bagnall, D. J. T. (1946). Brit. J. Radiol., 19, 505.

Ford, Daniel P. v. Union Stock Yards and Transit Co. (1942). Legal Case Report No. O.D. 1767, Industrial Commission of Illinois, U.S.A.

Hertzog, A. J., Smith, T. S., and Goblin, M. (1949). Pediatrics, $4,331$.

Hinson, K. F. W., Moon, A. J., and Plummer, N. S. (1952). Thorax., $7,317$.

Holden, G W (1915). Trans. Amer clin climat Ass. 31, 97.

Raether, F. (1912). Ueber Pneumonomykosis aspergillina. Inaug. Diss. Lehmann, Leipzig.

Richards, M. (1956). Trans. Brit. mycol. Soc., 39, 431.

Steele, A. E. (1926). Boston med. surg. J., 195, 536.

Tscherniak, W. S. (1928). Arch. wiss. prakt. Tierheilk, 57, 417.

Utz, J. P., German, J. L., Louria, D. B., Emmons, C. W., and Bartter, F. C.'(1959). New Engl. J. Med., 260, 264.

Wahl, E. F. (1928). J. Amer. med. Ass., 91, 200.

Wohlhueter, G., Kleitz, M., Kraft, J., and Mourot, G. (1940). Arch. Mal. prof., 2, 653 . 